Synthetic Resin Chemistry

For Students. By Dr. S. R. W. Martin. Pp. vii +160. (London: Chapman and Hall, Ltd., 1947.) $15 s$. net.

$\mathrm{D}^{\mathrm{n}}$ R. MARTIN'S book is best considered as an extremely practical guide to laboratory experiments for the student of synthetic resin chemistry, interspersed with an introductory survey of the theoretical side of this complicated field. The fiftyodd experiments are novel and well chosen; and it is difficult to know where else one could find details of such an illuminating series. They are simple, they are specific, and they work. On this score the book is wholly admirable.

Nevertheless, it is perhaps not unfair to doubt whether the accompanying theoretical matter, condensed and simplified though it is, will be smoothly absorbed by the type of reader visualized by the author in his preface-the student whose chemistry is of school certificate standard. This is no carping criticism; for the difficulty is one which must be faced squarely by anyone attempting to instruct the junior student in a technological subject with organic chemistry as its fundamental basis. True, the author devotes some twenty pages to a survey of elementary organic chemistry; but this alone is likely to prove heavy fare for the young chemist fresh from a school certificate course. It would appear essential to stipulate, not merely to hope for, "an elementary knowledge of organic chemistry" as a proper basis for the appreciation of the book. Taken, however, not on its own, but as an accompaniment (or, better, as a sequel) to a systematic elementary course in both aliphatic and aromatic chemistry, the book will be an invaluable guide to the embryo surface-coating technologist.

It may be hoped that in any subsequent edition the author will broaden slightly his title and terms of reference so as to include the cellulosic materials. As it stands, the book is useful only to the student in that section of the surface-coating industry dealing with phenoplastics, aminoplastics and alkyds: expanded slightly, its usefulness would extend to workers in all sections of the field.

\section{P. D. RITChIE}

\section{The Framework of Human Behaviour}

By Dr. Julian Blackburn. (International Library of Sociology and Social Reconstruction.) Pp. viii +158. (London : Kegan Paul and Co., Ltd., 1947.) 12s. 6d. net.

7 HIS book, presenting in small compass an extraordinary mass of learning and research, the research of others being amply acknowledged, deals, as the title says, with the framework of human behaviour. That framework connotes the equipment with which any person is endowed before he begins his individual development in society. Part of this endowment is due to hereditary factors, and part to the kind of environment in which he has been born. In this book, by no means the author's first production on the subject, he considers the part played by heredity and environment in the physical and mental make-up of individuals, and the part played by sex and racial differences. He then goes on to discuss the behaviour of groups, national and social, and the influences by which they are motivated. The reader will need to know something of the modern psychologist's use of the word 'pattern'definable as a complex whole, characterized by a definite arrangement or interrelation of parts; as a behaviour pattern or a pattern of brain activity, Many readers will find good use for the eighth chapter. entitled "Conclusion". The abounding references to other books are minutely careful. Dr. Blackburn has, in publishing this volume, made a substantial addition to the International Library of Sociology and Social Reconstruction.

\section{What People Are}

A Study of Normal Young Men. By Clark W. Heath, in collaboration with Lucien Brouha, Lewise W. Gregory, Carl C. Seltzer, Frederic L. Wells and William L. Woods. Pp. xvi $+141+4$ plates. (Cambridge, Mass. : Harvard University Press; London : Oxford University Press, 1946.) 11s. 6d. net.

7 HIS book should be welcome if only because it deals with an unusual subject. In both Britain and the United States much time, energy and financial support have been given to investigations of the mentally and physically ill and handicapped; but little attention has been paid to well people, upon whom depend the leadership and work of the world. Yet knowledge of the normal is of great concern in medicine, education, business and government. This report is based chiefly upon the study of selected Harvard undergraduates, but groups of men in the aimed forces and in civilian life have been investigated as well. Selection of college students was made on the basis of all-round good adjustment, good health and academic success. The approach is clinical. Characteristics of normal young men are described from the points of view of medicine, physiology, anthropology, mental measurements, socio-economics and psychiatry.

The authors make no pretence that this is a completed work, or that they have the answers to many important problems which they have presented. The field is a large one and much remains to be done.

One word more. We in Britain are bound to ask what about the normal young women, who are by no means content to leave all the leadership to the men, whether in medicine, education, business, or government?

\section{Making Your Own Telescope}

By Allyn J. Thompson. Pp. xi+211. (Cambridge, Mass. : Sky Publishing Corporation, 1947.) 3.50 dollars.

TELESCOPE making by amateurs has a great vogue in the United States. In association with the Hayden Planetarium in New York, there has, for almost a dozen years, been an Optical Division of the Amateur Astronomers Association. Facilities and space have been provided in the basement of the Planetarium for classes in telescope making. Mr. Thompson has for some years been the instructor of these classes and has had ample opportunity to develop and test efficient and practicable methods and to become familiar with the various pitfalls and difficulties that beset the beginner. In order to make available to a greater number of amateurs the experience that he has gained, this book has been written. It describes in some detail the methods of grinding, polishing, figuring and testing mirrors, as well as methods of correcting the more common defects, with many useful hints. The other parts of the telescope are not neglected, and descriptions are given of simple pipe mountings, the construction of which does not require much mechanical ability. 